\title{
Hubungan Peran Keluarga dengan Kecemasan Akibat Hospitalisasi pada Anak Prasekolah
}

\author{
${ }^{1}$ SYAFRIANI, ${ }^{2}$ FAYUDI KURNIAWAN \\ ${ }^{1}$ Program Studi Sarjana Kesehatan Masyarakat Universitas Pahlawan \\ Tuanku Tambusai, ${ }^{2}$ Program Studi Sarjana Keperawatan Universitas \\ Pahlawan Tuanku Tambusai \\ Email: ${ }^{1}$ syafrianifani@ymail.com, ${ }^{2}$ fayudi0908@gmail.com
}

Article Received: 17-07-2018

Published Article: 07-11-2018

DOI: https://doi.org/10.29313/ga.v2i1.3858

\begin{abstract}
The purpose of this study was to determine the relationship between the role of the family and anxiety due to hospitalization in preschool children in the inpatient room of Sungai Buluh Health Center, Beringin Jaya Health Center and Sungai Sirih Health Center in 2016. The design of this study used a quantitative design with cross-sectional approach. The sampling technique uses incidental sampling. Data analysis was performed with the chisquare test technique. The results showed a relationship between the role of the family and anxiety due to hospitalization in preschool children where the $p$-value $=0.012<a$

$=0.05$. Based on the results of the study there is a significant relationship between the role of the family and anxiety due to hospitalization in preschool children. The results of this study are expected to be used as an evaluation material for the Sungai Buluh Health Center, Beringin Jaya Health Center and Sungai Sirih Health Center to provide playrooms for children who are cared for so that children's anxiety is reduced.
\end{abstract}

Keywords: Anxiety, and Family Role

\begin{abstract}
Abstrak
Tujuan penelitian ini adalah untuk mengetahui hubungan peran keluarga dengan kecemasan akibat hospitalisasi pada anak prasekolah diruang rawat inap Puskesmas Sungai Buluh, Puskesmas Beringin Jaya dan Puskesmas Sungai Sirih Tahun 2016. Desain penelitian ini menggunakan desain kuantitatif dengan pendekatan cross sectional. Tehnik pengambilan sampel menggunakan acidental sampling. Analisis data dilakukan dengan tekhnik uji chi square. Hasil penelitian menunjukkan adanya hubungan antara peran keluarga dengan kecemasan akibat hospitalisasi pada anak prasekolah dimana nilai $p$-value $=0,012<a$ $=0,05$. Berdasarkan hasil penelitian terdapat hubungan yang signifikan antara peran keluarga dengan kecemasan akibat hospitalisasi pada anak prasekolah. Hasil penelitian ini diharapkan dapat digunakan sebagai bahan evaluasi bagi Puskesmas Sungai Buluh, Puskesmas Beringin Jaya dan Puskesmas Sungai Sirih untuk memberikan ruangan bermain untuk anak-anak yang dirawat, sehingga kecemasan pada anak berkurang.
\end{abstract}

Kata Kunci: Kecemasan, dan Peran Keluarga.

\section{Pendahuluan}

Keperawatan anak telah mengalami perubahan yang sangat mendasar. anak tidak lagi dipandang miniatur orang dewasa, melainkan sebagai mahluk unik yang memiliki kebutuhan sepesifik dan berbeda dengan orang dewasa. Keluarga juga tidak dipandang sebagai pengunjung anak, melainkan sebagai mitra bagi petugas kesehatan dalam memenuhi kebutuhan anak (Riza, 2012).

Sakit merupakan suatu kondisi yang tidak dapat dipisahkan dari peristiwa kehidupan seseorang, sakit dapat menyebabkan perubahan fisik, mental dan sosial (Perry, 2005). Kondisi ini tidak hanya berpengaruh pada individu yang mengalami sakit namun juga berpengaruh terhadap keluarga, dan sebaliknya keluarga 
juga mempunyai pengaruh dengan kondisi tersebut.

Sakit dan dirawat di rumah sakit merupakan krisis utama yang tampak pada anak. Jika seorang anak di rawat, maka anak tersebut akan mudah mengalami kecemasan. Karena, anak mengalami cemas akibat perubahan baik terhadap status kesehatannya maupun lingkungannya dalam kebiasaan sehari-hari. Anak juga mempunyai sejumlah keterbatasan dalam mekanisme koping untuk mengatasi masalah maupun kejadian-kejadian yang bersifat menekan (Susilanigrum, 2005).

Hospitalisasimerupakan suatu proses karena alasan yang berencana dan darurat, yang mengharuskan anak untuk tetap tinggal dirumah sakit atau Puskesmas rawat inap untuk menjalani terapi dan perawatan sampai diperbolehkan untuk kembali kerumah. Selama hospitalisasi banyak kejadian yang sering dialami oleh anak dan keluarga seperti trauma dan stres serta perasaan cemas, marah, sedih, takut dan rasa bersalah (Wong, 2008).

Kecemasan pada anak khususnya anak usia prasekolah yang sakit dan harus dirawat inap, merupakan salah satu bentuk gangguan yaitu tidak terpenuhinya kebutuhan emosional yang adekuat. Hal ini perlu penanganan sedini mungkin, dampak dariketerlambatan dalam penanganan kecemasan anak akan menolak perawatan dan pengobatan. Maka dalam perawatan anak saat dirawat inap di Puskesmas rawat inap perlu penerapan model asuhan yang holistic yaitu harus ada dukungan sosial keluarga, lingkungan perawatan yang terapeutik dan sikap perawat yang penuh dengan perhatian yang akan mempercepat proses penyembuhan (Nursalam, 2009).

Perawatan anak prasekolah di Puskesmas rawat inap memaksakan anak berpisah dari lingkungan yang dirasakannya aman, penuh kasih sayang dan menyenangkan yaitu lingkungan rumah, teman dan teman sepermainannya. Reaksi terhadap perpisahan yang ditunjukkan pada anak prasekolah ialah dengan menolak makan, sering bertanya, menangis, dan tidak kooperatif terhadap petugas kesehatan dan membuat anak kehilangan kontrol dirinya (Nursalam, 2009).

Persepsi sakit dan hospitalisasi anak usia prasekolah adalah merasa sebagai hukuman sehingga anak merasa malu, bersalah atau takut. Ketakutan anak terhadap tindakan keperawatan muncul karena anak menganggap tindakan dan prosedurnya mengancam integritas tubuhnya. Oleh karena itu, hal ini menimbulkan reaksi agresif, yaitu dengan marah, berontak, tidak mau bekerja sama dengan perawat dan ketergantungan pada keluarga atau orang tua. Oleh sebab itu perlu peran keluarga, karena keluarga adalah unsur penting dalam perawatan, khususnya perawatan pada anak (Nursalam, 2009).

Peran keluarga adalah tingkah laku yang spesifik yang diharapkan oleh seseorang dalam konteks keluarga yang menggambarkan seperangkat perilaku interpersonal, sifat, kegiatan yang berhubungan dengan individu dalam posisi dan situasi tertentu (Setiadi, 2008).

Orang tua sangat berperan dalam perawatan anak selama di rumah sakit, anak membutuhkan kasih sayang dan perhatian orang tua yang lebih saat di rawat di rumah sakit. Secara umum respon orang tua terhadap hospitalisasi anak adalah rasa tidak percaya, marah, rasa bersalah, takut, cemas, stres dan frustasi. Ada enam hal yang menjadi stresor keluarga pada saat anak sakit yaitu diagnosis penyakit, tindakan pengobatan atau perawatan, ketidaktahuan merawat penyakit anak, kurangnya sistem pendukung, ketidakmampuan menggunakan mekanisme koping, dan kurangnya komunikasi antarkeluarga (Wong, 2008).

Untuk menghindari gangguan tumbuh kembang pada anak selama dirawat di Puskesmas rawat inap dewasa ini, orang tua pasien diizinkan menunggui anaknya agar pasien merasa terlindungi dan tidak ketakutan. Adanya orang tua disamping anak untuk menunggunya juga dapat dimintai tolong untuk hal-hal tertentu. Misalnya membujuk anaknya jika perlu mendapatkan pengobatan dengan suntikan atau perlu pemeriksaan lainnya seperti darah, rontgen, atau lainnya. Perawat perlu menginformasikan kepada keluarga agar memberitahu perawat dengan segera bila melihat anaknya kedinginan, kesakitan, atau gelisah, dengan demikian akan menimbulkan reaksi positif dari orang tuanya (Ngastiyah, 2005).

Orang tua didorong untuk tetap tinggal dengan anak-anak yang masih muda selama mungkin sehingga perilaku perpisahan diminimalkan. Kesediaan orang tua untuk tinggal bergantung kepada keterlibatan mereka dengan anak-anak dirumah, situasi kerja mereka, dan tingkat rasa nyaman mereka dengan puskesmas rawat inap, serta jumlah dukungan yang mereka terima dari anggota 
keluarga lain dan teman dalam memenuhi kebutuhan anggota keluargalainnya (Perry, 2005).

Menurut Lumiu (2013) ada hubungan bermakna tingkat kecemasan dengan dukungan keluarga, semakin besar dukungan yang diberikan keluarga maka semakin rendah kecemasan yang dialami anak sehingga anak merasa tenang, nyaman, merasa disayang dan diperhatikan oleh orang terdekatnya.

Data di Amerika serikat, diperkirakan lebih dari 5 juta anak menjalani hospitalisasi karena prosedur pembedahan dan lebih dari $50 \%$ dari jumlah tersebut, anak mengalami kecemasan dan stres. Selain itu pada tahun 2004 Disease Control, National Hospital Discharge Survey (NHDS)memperkirakan lebih dari 1,6 juta anak menjalani hospitalisasi disebakan karena injury dan berbagai penyebab lainnya dalam Apriliawati (2011).

Angka kesakitan anak di Indonesia berdasarkan Survei Kesehatan Nasional (SUSENAS) tahun 2010 yang dikutip oleh Apriany (2013), di daerah perkotaan menurut kelompok usia 0-4 tahun sebesar 25,8\%, usia 5-12 tahun sebanyak $14,91 \%$, usia $13-15$ tahun sekitar 9,1\%, usia 16-18 tahun sebesar $8,13 \%$. Angka kesakitan anak usia 0-18 tahun apabila dihitung dari keseluruhan jumlah penduduk adalah $14,44 \%$. Anak yang dirawat di ruang rawat inap akan berpengaruh pada kondisi fisik dan psikologinya, hal ini disebut dengan hospitalisasi.

Hasil data rekam medis RSUD Arifin Achmad Provinsi Riau pada bulan Desember 2014 jumlah anak diruang rawat inap flamboyan sebanyak 103, usia 0 -11 bulan 8 anak, usia 1-4 tahun 25 anak, usia 5-15 tahun 70 anak dan apabila dilihat dari jenis kelaminnya anak laki-laki sebanyak 76 anak dan anak perempuan sebanyak 33 anak dalam Oky (2015).

Data Kabupaten Kuantan Singingi terdapat 24 Puskesmas dan 10 diantaranya adalah Puskesmas rawat inap. Dari data dinas kesehatan Kabupaten Kuantan Singingi dapat dilihat jumlah kunjungan pasien anak yg dirawat di 10 Puskesmas rawat inap pada bulan Januari-Desember tahun 2015, yaitu Puskesmas Sungai Buluh 109 anak, Puskesmas Bringin Jaya 75 anak, Puskesmas Muara Lembu 40 anak, Puskesmas Sungai Sirih 69 anak, Puskesmas Lubuk Jambi 62 anak, Puskesmas Sentajo Raya 17 anak, Puskesmas Suka Raja 43 anak, Puskesmas Perhentian Luas 22 anak, Puskesmas Baserah
58 anak, dan Puskesmas Cerenti 60 anak.

Hasil data rekam medis Puskesmas Sungai Buluh jumlah anak yang di rawat inap di Puskesmas Sungai Buluh pada bulan Januari- Desember 2015 pasien anak sebanyak 109, anak laki-laki sebanyak 68 anak dan anak perempuan sebanyak 41 anak. Puskesmas Beringin Jaya jumlah anak yang di rawat inap sebanyak 75 anak, anak laki-laki 43 dan anak perempuan 32 . Untuk Puskesmas Sungai sirih jumlah anak yang di rawat inap sebanyak 69 anak, anak laki-laki 40 dan anak perempuan 29.

Survei awal yang dilakukan peneliti dengan mewawancarai 10 orang keluarga yang anaknya dirawat di Puskesmas Sungai Buluh didapatkan bahwa 6 orang keluarga mengatakan ketika anaknya akan dilakukan tindakan keperawatan seperti pemeriksaan tanda-tanda vital, pemeriksaan labor dan pemberian obat oral maupun injeksi anak mengalami cemas, saat anak cemas keluarga tidak mampu melakukan peranya sebagai keluarga, sedangkan 4 orang keluarga mengatakan anaknya tidak cemas di karenakan keluarga mampu membujuk dan memberikan motivasi terhadap anaknya.

Penelitian ini tidak bisa dilakukan di RSUD Taluk Kuantan di karenakan RSUD Taluk Kuantan sedang mengalami permasalahan yang tidak bisa dijelaskan secara rinci oleh peneliti,dimana permasalahan tersebut mempengaruhi jumlah kunjungan pasien anak.

Berdasarkan latar belakang diatas maka peneliti tertarik untuk melakukan penelitian dengan judul "Hubungan Peran Keluarga Dengan Kecemasan Akibat Hospitalisasi Pada Anak Prasekolah Diruang Rawat Inap".

\section{Metode Penelitian}

\section{Desain Penelitian}

\begin{abstract}
Penelitian ini merupakan penelitian dengan desain cross sectional study. Penelitian ini menganalisis hubungan variabel dependent (peran keluarga) dengan variabel Independent (pengetahuan,kecemasan akibat hospitalisasi).
\end{abstract}

\section{Lokasi dan Waktu Penelitian}

Lokasi penelitian di Puskesmas Sungai Buluh, Puskesmas Beringin Jaya dan Puskesmas Sungai Sirih Kabupaten Kuantan 
Singingi.Penelitian ini dilakukan pada tanggal 25 Juli sampai 31 Agustus 2016.

\section{Populasi}

Populasi dalam penelitian ini adalah seluruh keluarga yang memiliki anak usia prasekolah (3-6 tahun) yang dirawat di Puskesmas Sungai Buluh, Puskesmas Beringin Jaya dan Puskesmas Sungai Sirih pada tanggal 25 Juli sampai 16 Agustus 2016

\section{Sampel}

Teknik sampling pada penelitian ini menggunakan teknik Accidental Sampling yaitu subyek yang dijadikan sampel adalah orang yang dijumpai saat itu saja. Adapun jumlah sampel dalam penelitian ini yaitu sebanyak 40 sampel.

\section{Alat Pengumpulan Data}

Pada penelitian ini untuk mengetahui peran keluarga dengan menggunakan kuesionersebagai alat pengumpul data. Kuesioner pada penelitian ini berisikan pertanyaan-pertanyaan yang mengacu pada variabelindependen itu mengenai peran keluarga mengatasi kecemasan anak yang terdiri dari 15 pertanyaan. Pertanyaan ini diambil dari penelitian orang lain. Pertanyaan yang menyangkut varibel depedentdari 20 pertanyaan, dengan menggunakan Hamilton Anxiety Rating Scale (HARS). Skala HARS merupakan pengukuran kecemasan yang didasarkan pada munculnya symptom pada individu yang mengalami kecemasan. Menurut skala HARS terdapat 14 syptoms yang nampak pada individu yang mengalami kecemasan.

\section{Analisa Data}

Analisa yang digunakan adalah analisa univariat dan analisa bivariat. Analisis bivariat menggunakan uji chi-square dengan tingkat kepercayaan $95 \%$ dan tingkat kemaknaan $p$ value $<0,05$. Analisa data menggunakan bantuan program komputerisasi.

\section{Hasil dan Pembahasan \\ Hasil Penelitian \\ Analisis Univariat}

Berdasarkan pengumpulan data umum melalui penyebaran kuesioner terhadap 40 responden di Wilayah Kerja UPTD Sungai Sirih didapatkan karakteristik responden berdasarkan kelompok umur,hubungan dengan pasien dan peran keluarga serta kecemasan anak. Dari 40 responden sebagian besar responden berusia 5-6 tahun yaitu sebanyak 22 orang (55 \%). Sedangkan hubungan dengan pasien, dari 40 responden sebagian besar yang mendampingi pasien adalah ibu sebanyak 28 orang (70 \%). Untuk jenis kelamin dari 40 responden sebagian besar anaknyaberjenis kelamin perempuan sebanyak 24 orang $(60.0 \%)$ dan dari 40 responden sebagian besar peran keluarganya kurang baik sebanyak 19 orang (47.5 $\%)$.Serta dari 40 respondensebagian besar memiliki cemas sebanyak 24 orang $(60 \%)$.

\section{Analisa Bivariat}

Analisis bivariat adalah analisis yang digunakan untuk melihat hubungan antara variabel bebas dengan variabel terikat. Uji yang dilakukan adalah uji statistik dengan Chi-square. Suatu variabel independen dinyatakan mempunyai hubungan yang bermakna jika hasil uji statistiknya memperoleh nilai $p<0,05$ dengan derajat kepercayaan 95\% maka didapat hasil sebagai berikut:

\section{HubunganPeran Keluarga Dengan Kecemasan}

Berdasarkan hasil penelitian diketahui bahwa dari 40 sampel11 responden denganperan keluarga yang baik, terdapat 4 orang $(36,4 \%)$ mengalami cemas, dari 10 responden dengan peran keluarga yang cukup baik, terdapat 4 orang (40\%) mengalami cemas dan dari 19 responden dengan peran keluarga yang kurang baik, terdapat 3 orang $(15,9 \%)$ tidak cemas.

Berdasarkan hasil uji statistik menggunakan uji chi - Squaredi peroleh Pvalue sebesar 0,012 yang berarti $P$-value $<$ a 0,05. Hal ini berarti HO ditolak sehingga terdapat hubungan yang signifikan antara peran keluarga dengan kecemasan akibat hospitalisasi pada anak prasekolah di ruang rawat inap Puskemas Sungai Buluh, Puskesmas Beringin Jaya, Dan Puskesmas Sungai Sirih. 


\section{Pembahasan}

\section{Analisa Bivariat}

Hubunganperan keluarga dengan kecemasanakibat hospitalisasi pada anak prasekolah di Puskesmas Sungai Buluh, Puskesmas Beringin Jaya dan Puskesmas Sungai Sirih

Hasil analisis hubungan peran keluarga dengan kecemasan akibat hospitalisasi pada anak prasekolah di Puskesmas Sungai Buluh, Puskesmas Beringin Jaya dan Puskesmas Sungai Sirih dengan menggunakan uji chiSquare menunjukkan nilai $P$-value sebesar 0,012, dimana $P$-value $<a \quad(0,05)$. Hal ini menunjukkan bahwa HO ditolak, sehingga dapat disimpulkan bahwa terdapat hubungan antara peran keluarga dengan kecemasan akibat hospitalisasi pada anak prasekolah di ruangan rawat inap Puskesmas Sungai Buluh, Puskesmas Beringin Jaya dan Puskesmas Sungai Sirih. Dari hasil penelitian menunjukan bahwa dari 11 peran keluarga baik terdapat 4 orang $(36,4 \%)$ yang cemas. Dari 10 peran keluarga cukup baik terdapat 4 orang (40\%) yang cemas dan dari peran keluarga kurang baik sebanyak 19 orang terdapat 3 orang $(15,9 \%)$ yang tidak cemas.

Hasil penelitian yang dilakukan oleh Casmirah (2011) yang meneliti tentang hubungan peran orang tua dengan kecemasan anak dengan nilai $0,001<a 0,05$, dimana peran orang tua berperan cukup signifikan, hal ini perlu diperhatikan bahwa peran orang tua dimasa usia prasekolah perlu dilakukan, karena anak prasekolah memerlukan bimbingan, petunjuk serta kasih sayang.

Sakit dan dirawat di rumah sakit merupakan krisis utama yang tampak pada anak. Jika seorang anak di rawat, maka anak tersebut akan mudah mengalami kecemasan. Karena, anak mengalami cemas akibat perubahan baik terhadap status kesehatannya maupun lingkungannya dalam kebiasaan sehari-hari. Anak juga mempunyai sejumlah keterbatasan dalam mekanisme koping untuk mengatasi masalah maupun kejadian-kejadian yang bersifat menekan (Susilanigrum, 2005).

Perankeluarga di paparkanoleh Chen (2006)menjelaskan bahwa bentuk peran serta keluarga selama anak di rawat di rumah sakit adalah dengan menjalin kolaborasi antara orang tua dengan profesi kesehatan dan kehadiran orang tua yang dapat memberikan rasa nyaman pada anak. Bentuk kolaborasi orang tua dan profesi kesehatan di wujudkan dengan adanya keterlibatan orang tua dalam perawatan, memberikan support emosional kepada anak, ikut terlibat padat indakan yang sederhana, menjelaskan kepada anak tentang kondisi anak dan memenuhi kebutuhan anak selama di rawat.

Peran orang tua di samping anak bukan semata-mata hanya memperhatikan rasa sakit anak, tetapi lebih kepada sikap mental serta mampu menjadi pendorong semangat anak, dimana anak merasa aman dan nyaman. Untuk itu, orang tua juga harus bisa selalu tampak bahagia, senang dalam menghadapi tingkah laku anak, baik secara ekspresi, ucapan dan hati. Selanjutnya tinggal bagaimana caranya agar anak sekalipun dalam masa perawatan tetap bisa mendapatkan stimulus yang berguna. Dengan demikian, selain dapat membantu mempercepat kesembuhanya, si anak pun bisa tetap belajar dan dapat mengurangi kecemasan (Wong, 2008).

Berdasarkan uraian diatas peneliti berasumsi bahwa, hubungan peran keluarga dengan kecemasan akibat hospitalisasi pada anak prasekolah sangat signifikan. Dari 11 orang yang peran keluarganya baik terdapat 4 orang $(36,4 \%)$ yang cemas, ini disebabkan karena tidak semua anak prasekolah memahami dan mengerti apa yang sudah di lakukan oleh keluarganya dan tidak semua anak merasa nyaman dengan lingkungan dan kegiatan hospitalisasi yang ada di ruangan rawat inap Puskesmas. Sedangkan dari 19 peran keluarga kurang baik terdapat 3 orang $(15,9 \%)$ yang tidak cemas. Halini disebabkan karena anak sudah pernah dirawat sebelumnya, sehingga anak sudah terbiasa dengan lingkungan puskesmas rawat inap dan mengerti tujuan dari hospitalisasi.

\section{Kesimpulan}

Dari hasil penelitian maka dapat disimpulkan bahwa :

Diketahui distribusi frekuensi peran keluarga dalam mengatasi kecemasan hospitalisasi pada anak prasekolah di ruang rawat inap Puskesmas Sungai Buluh, Puskesmas Beringin Jaya dan Puskesmas Sungai Sirih sebagian besar peran keluarganya kurang baik.

Diketahui distribusi frekuensi kecemasan anak akibat hospitalisasi pada anak prasekolah diruang rawat inap Puskesmas Sungai Buluh, 
Puskesmas Beringin Jaya dan Puskesmas sungai Sirih dimana dari 40 orang responden sebagian besar mengalami cemas.

Berdasarkan hasil uji chi- Square terdapat hubungan peran keluarga dengan kecemasan akibat hospitalisasi pada anak prasekolah di ruang rawat inap Puskesmas Sungai Buluh, Puskesmas Beringin Jaya dan Puskesmas Sungai Sirih.

\section{Saran}

Berdasarkan penelitian yang telah dilakukan, penulis memberikan saran-saran sebagai berikut :

\section{Bagi Instansi Kesehatan}

Hasil penelitian ini diharapkan dapat digunakan sebagai bahan evaluasi bagi Puskesmas Sungai Buluh, Puskesmas Beringin Jaya dan Puskesmas Sungai Sirih untuk memberikan ruangan bermain untuk anak-anak yang dirawat, sehingga kecemasan pada anak berkurang.

\section{Bagi Keluarga}

Hasil penelitian ini diharapkan dapat meningkatkan peran keluarga dalam mengatasi kecemasan anak prasekolah sehingga saat anaknya dirawat tidak lagi merasakan cemas.

\section{Institusi Pendidikan}

Hasil penelitian ini diharapkan dapat menjadikan sebagai data dasar bagi peneliti selanjutnya dibidang kesehatan, khususnya tentang hubungan peran keluarga dengan kecemasan akibat hospitalisasi pada anak prasekolah dan juga diharapkan dapat dipergunakan sebagai bahan perpustakaan.

\section{Peneliti Selanjutnya}

Diharapkan bagi peneliti lain yang tertarik dengan penelitian tentang hubungan peran keluarga dengan kecemasan akibat hospitalisasi pada anak prasekolah dapat menjadikan penelitian ini sebagai acuan awal dan melanjutkan dengan variabel lain yang berhubungan dengan peran keluarga dengan kecemasan anak prasekolah.

\section{Daftar Pustaka}

Apriany, D. (2013). Hubungan antara hospitalisasi anak dengan tingkat kecemasan orang tua. Jurnal Keperawatan Soedirman, (Nomor 2, halaman 92-104).

Apriliawati, A. (2011). Pengaruh biblioterapi terhadap tingkat kecemasan anak usia sekolah yang menjalani hospitalisasi dirumah sakit islam jakarta. Thesis. Depok: Universitas Indonesia.

Canam. (2008). Peran keluarga dalam proses hospitalisasi. https://www.google.com/

?client $=$ firefoxa $\# \mathrm{q}=\mathrm{bab}+2+$ peran + kelu arga+dalam+hospitalisasi\&gws_rd=ssl. Diperoleh tanggal 15 April 2016.

Efendi, F. (2009). Keperawatan Komunitas Teori Dan Praktik Dalam Keperawatan. Jakarta: Salemba Medika.

Friedman, Marilyn. M. (2010). Keperawatan Keluarga: Teori Dan Praktik. Jakarta: EGC.

Ghufron, M. N., \& Rini, R. S. (2014). TeoriTeori Psikologi. Yogyakarta: Ar-Ruzz Media.

Hidayat, A. A. (2010). Metode Penelitian Kebidanan Dan Teknik Analisis Data. Jakarta: Salemba Medika.

Hidayat, A. A. (2011). Metode Penelitian Keperawatan Dan Teknik Analisa Data. Jakarta: Salemba Medika.

Irdawati \& Wibowo, T. A. (2010). Analisis hubungan support system keluarga dengan tingkat kecemasan anak prasekolah yang dirawat di rsud dr. Moewardi surakarta. Jurnal Keperawatan Soedirman, (Nomor 3, halaman 120-126).

Keliat, a. B., Wiyono., \& Susanti. (2011). Manajemen Kasus Gangguan Jiwa: CMHN (Intermediate Course). Jakarta: EGC.

Kozier Barbara. (2008). Definisi Peran. h t t p://repository.usu.ac.id $\angle$ bitstream/123456789/2 $4955 / 4 /$ Chapter\%20II.pdf. Diperoleh tanggal 3 April 2016.

Lumiu, S. E. (2013). Hubungan dukungan keluarga dengan tingkat kecemasan akibat hospitalisasi pada anak di usia pra sekolah di irina E Blu Prof Dr.R.D. Kandou Manado.Ejournal Keperawatan, (Nomor 1).

Ngastiyah. (2005). Perawatan Anak Sakit. Jakarta: EGC.

Notoatmodjo, S. (2010). Metodologi Penelitian Kesehatan (ed. Rev). Jakarta: Rineka Cipta.

Notoatmodjo, S. (2012). Metodologi Penelitian Kesehatan (ed. Rev). Jakarta: Rineka Cipta.

Nursalam. (2009). Pedoman Praktis 
Penyusunan Riset Keperawatan. Surabaya: Universitas Airlangga.

Nursalam. (2011). Manajemen Keperawatan, Aplikasi Dalam Praktik Keperawatan Profesional. Jakarta: Salemba Medika.

Potter, P. A., \& Perry, A. G. (2005). Buku Ajar Fundamental Keperawatan: Konsep Proses Dan Praktik. Jakarta: EGC.

Setiadi. (2008). Konsep Dan Proses Keperawatan Keluarga. Yogyakarta: Graha Ilmu.

Setiawan, A., \& Saryono. (2011). Metodologi Penelitian Kebidanan DIII, DIV, S1 dan S2. Yogyakarta: Nuha Medika.

STIKes Tuanku Tambusai Riau. (2015). Panduan Penulisan Karya Tulis IImiah Mahasiswa.
Stuart, G. W. (2007). Keperawatan Jiwa. Edisi Kelima. Jakarta: EGC.

Sugiono. (2011). Metode Penelitian Kuantitatif, Kualitatif Dan Kombinasi (Mixed Methods). Bandung: Alfabeta.

Sujarweni, V. W. (2014). Metodologi Penelitian. Yogyakarta: Pustaka Baru Press.

Supartini, Y. ( 2012). Buku Ajar Konsep Dasar Keperawatan Anak. Jakarta: EGC.

Videbeck, S. L. (2008). Buku Ajar Keperawatan Jiwa. Jakarta: EGC.

Wong, D. (2008). Buku Ajar Keperawatan Pediatrik, Edisi, 6. Jakarta: EGC. 